\title{
EARTHQUAKE OBSERVATION SYSTEM FOR TELECOMMINUCATION BUILDINGS AND EQUIPMENT IN JAPAN
}

\author{
Hisanobu AKAGI ${ }^{1}$ and Hiroshi DOHI ${ }^{2}$ \\ ${ }^{1}$ Executive Vice President, NTT BUILDING TECHNOLOGY INSTITUTE, Tokyo, Japan, \\ akagi@ntt-bti.co.jp \\ ${ }^{2}$ Manager, Research and Development Headquarters, NTT FACILITIES INC., Tokyo, Japan, \\ dohi@rd.ntt-f.co.jp
}

\begin{abstract}
This paper presents the NTT and NTT FACILITIES earthquake observation system for earthquake resistant (low-rise, middle-rise, and high-rise building), vibration controlled, and base isolated buildings. The example of observation data of the Hyogo-ken Nanbu earthquake and the application of data for earthquake resistant design and shaking table test are described too.
\end{abstract}

Key Words: Earthquake observation of building, Hyogo-ken Nanbu earthquake, Earthquake measurement, Telecommunication, Equipment

\section{INTRODUCTION}

In recent years, the large earthquakes have frequently occurred near urban areas and caused enormous damages to structures and facilities. Ground motions are strongly conditioned by site amplification, propagation path, and source rupture process. Moreover seismic waves to human beings and equipment in a building are influenced by the vibration characteristic of the building structure. So it is very important for earthquake measurement and seismic design to estimate earthquakes by observational and analytical methods, and to take them into total consideration.

The earthquake observation sites on Japanese ground have been rapidly increased after the Hyogo-ken Nanbu earthquake (1995). However, the observation sites for building structures are not enough yet.

NTT (Nippon Telegraph and Telephone Corporation) and NTT FACILITIES have developed seismic design and vibration test methods for telecommunication buildings and equipment in order to secure the reliability and safety of telecommunication. The earthquake observation system has been constructed since 1960.

This paper presents the NTT and NTT FACILITIES earthquake observation system for earthquake resistant (low-rise, middle-rise, and high-rise building), vibration controlled, and base isolated buildings. The example observation data of the Hyogo-ken Nanbu earthquake and the application of these data to earthquake resistant design and shaking table test are described too. 


\section{EARTHQUAKE OBSERVATION SYSTEM}

Fig. 1 shows observation site map for earthquake resistant buildings, vibration controlled buildings, and base isolated buildings. There are 55 sits in Japan. The 35 low- and middle-rise earthquake resistant buildings are usually equipped with SMAC type seismographs on the ground floor and the top floor. On the other hand, high-rise, vibration controlled, and base isolated buildings have the digital type seismographs which can simultaneously observe earthquakes at various points like near to the building ground level, foundation, building floors, and tower on buildings.

Fig. 2 shows the Yokohama Media Tower with earthquake observation system using digital type seismographs. The building located in latitude $35^{\circ} 27^{\prime} \mathrm{N}$ and longitude $139^{\circ} 37^{\prime} \mathrm{E}$ is a steel-framed structure with vibration control walls. On the top of building is a steel framed tower.

In the building and the tower are 5 seismographs, which are connected to a Web server in the first ground floor by local area network and portable phones. Each seismograph observes 3 component acceleration data. The data saved in Web server is forwarded to the central server located in another NTT FACILITIES' building by the telecommunication network.

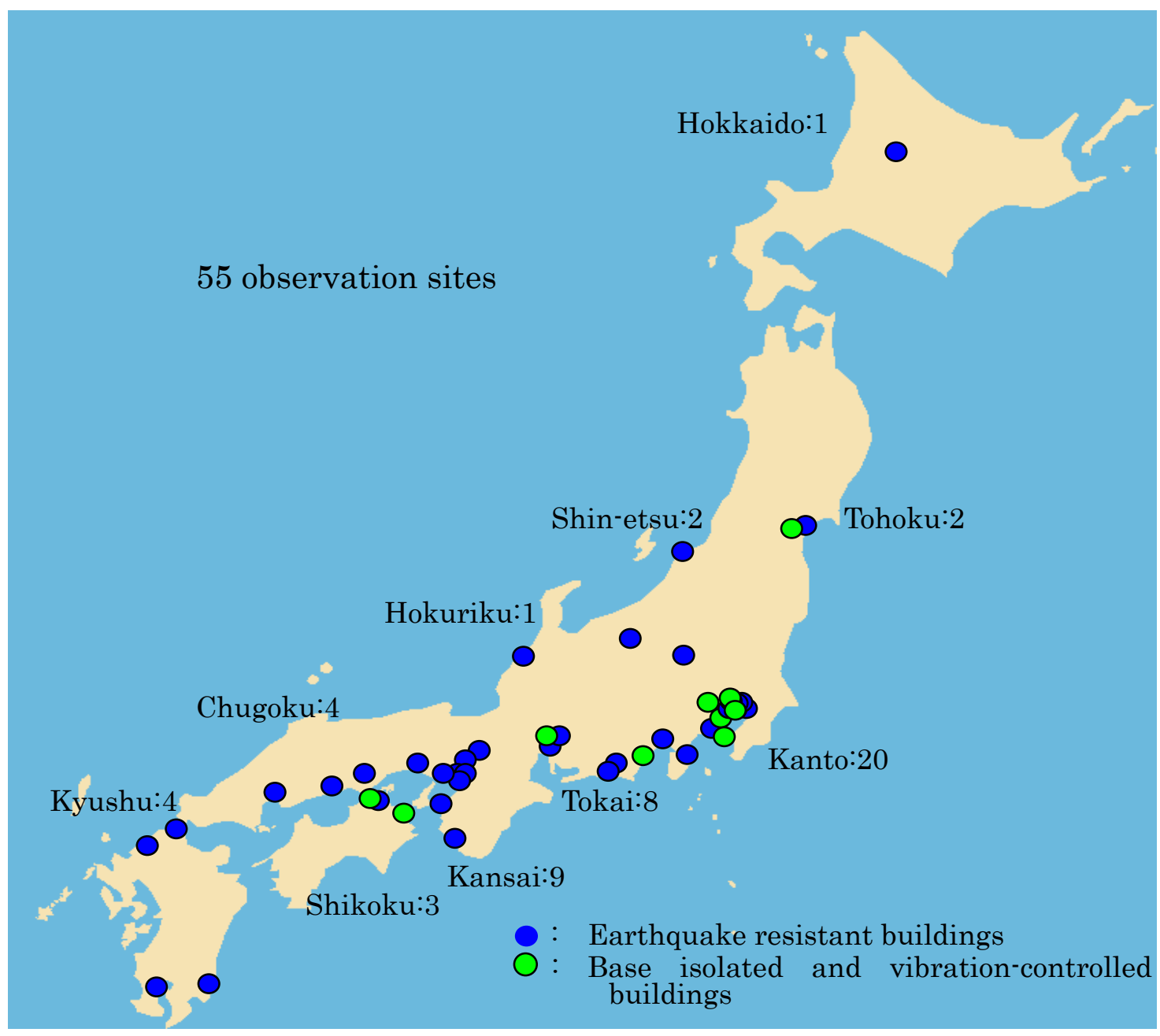

Fig. 1 Observation site map 


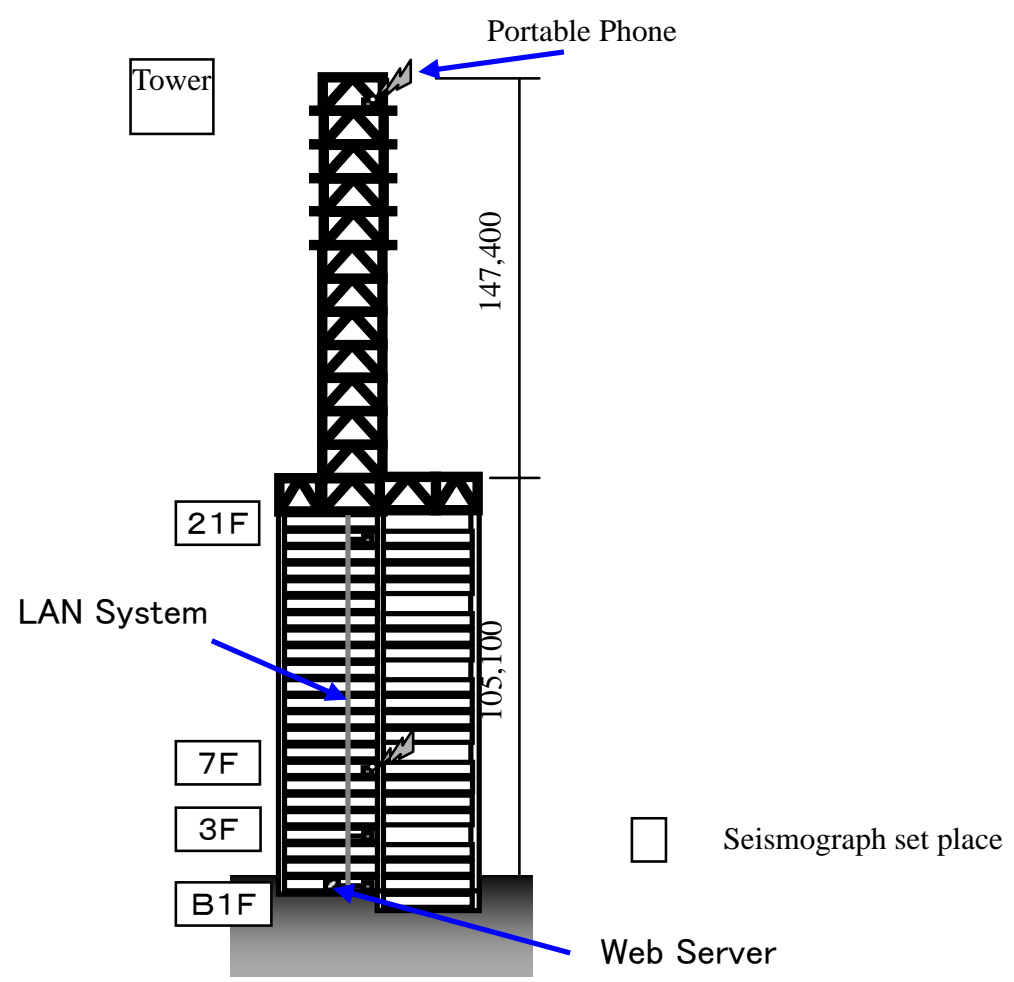

Fig. 2 Section view of Yokohama Media Tower and location of seismographs (in mm)

\section{EARTHQUAKE RECORDS}

Tremendous amounts of data were observed since the first SMAC type seismograph has been installed in an earthquake resistant building in 1960. In this paper, the Hyogo-ken Nanbu earthquake data observed in the NTT Kobe Ekimae Building are presented.

The NTT Kobe Ekimae Building (built in 1972, latitude $34^{\circ} 41^{\prime} 10^{\prime \prime}$ N. and longitude $135^{\circ} 12^{\prime} 24^{\prime \prime}$ E.) is located in an area which was designated as 6th degree seismic intensity of Japan Meteorological Agency at the 1995 Hyogo-ken Nanbu Earthquake. The distance from epicenter to the building was about 17km. Fig. 3 shows the location of the site and the fault segments. Fig. 4 shows the site plan, a plan of the 3rd ground floor, and a section view of this building. The building of a SRC structure has eight stories above the ground and three stories underground. Its foundation is a direct foundation on the bearing ground at GL-16m which is composed of sand and gravel layer. The geological data of soil sediment from GL to GL-65m is shown in Table 1. The P-wave and S-wave velocities of the soil sediment are investigated by PS logging.

The damage caused by the Hyogo-ken Nanbu Earthquake to this building was relatively low. The shear ruptures occurred on some of the anti-seismic walls with an opening from the 2nd to 5th story. No more than $1 \mathrm{~mm}$ wide cracks were observed on the other structural members.

The seismographs shown in Fig. 4 are located on the 8th floor and the 3rd ground floor of the NTT Kobe Ekimae Building. The sense of the seismographs was adjusted in the direction of the building axis, namely the direction of the building's length-wise side $\left(\mathrm{N} 309^{\circ} \mathrm{E}\right)$, the building's shorter width-wise side $\left(\mathrm{N} 219^{\circ} \mathrm{E}\right)$, and in the vertical direction. The acceleration time histories of the observed seismic motions at the 3rd ground floor in the direction of NS, EW and vertical are shown in Fig. 5.

In this earthquake, the strong earthquake data could hardly observed in Kobe city, because just a few observation sites and systems were in this area at that time. So it is said that the NTT Kobe Ekimae Building's data are very important and valuable. The data have been opened to public and were used for earthquake response analysis to design a lot of high-rise buildings and base isolated buildings in Japan. 
Table 1 Geological data of soil sediment at the NTT Kobe Ekimae Building

\begin{tabular}{ccccccc}
\hline $\begin{array}{c}\text { Depth } \\
(\mathrm{m})\end{array}$ & Soil & $\begin{array}{c}\text { Density } \\
\left(\mathrm{x} 10^{3} \mathrm{~kg} / \mathrm{m}^{3}\right)\end{array}$ & $\begin{array}{c}\text { Vp } \\
(\mathrm{m} / \mathrm{s})\end{array}$ & $\begin{array}{c}\text { Vs } \\
(\mathrm{m} / \mathrm{s})\end{array}$ & $\begin{array}{c}\text { Poisson } \\
\text { ratio }\end{array}$ & $\begin{array}{c}\text { Damping } \\
(\%)\end{array}$ \\
\hline GL0-2.0 & cobble stone & 1.6 & 410 & 90 & 0.475 & 2.0 \\
\hline $2.0-5.0$ & sand & 1.8 & 1500 & 130 & 0.496 & 2.0 \\
\hline $5.0-10.0$ & sand with gravel & 1.9 & 1500 & 190 & 0.492 & 2.0 \\
\hline $10.0-20.0$ & sandy & 1.9 & 1720 & 250 & 0.489 & 2.0 \\
\hline $20.0-38.0$ & sandy & 2.0 & 1820 & 410 & 0.473 & 2.0 \\
\hline $38.0-46.0$ & clay & 2.0 & 1820 & 410 & 0.473 & 2.0 \\
\hline $46.0-52.0$ & sand with gravel & 2.0 & 1820 & 410 & 0.473 & 2.0 \\
\hline $52.0-54.0$ & sand with gravel & 1.9 & 1620 & 360 & 0.474 & 2.0 \\
\hline $54.0-65.0$ & clay & 1.9 & 1620 & 360 & 0.474 & 2.0 \\
\hline
\end{tabular}

Fig. 3 Location of NTT Kobe Ekimae Building and fault segments of Hyogo-ken Nanbu earthquake

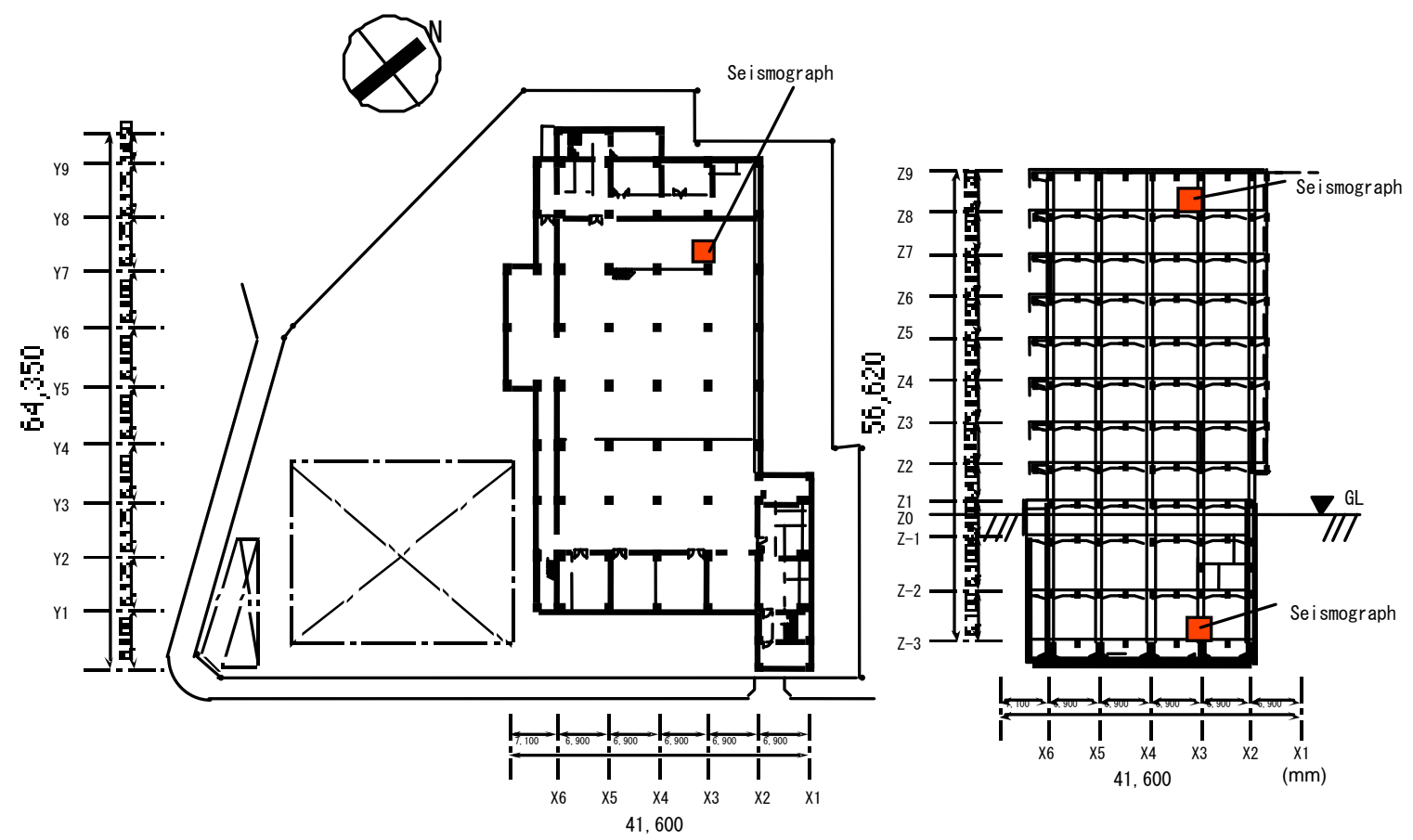

Fig. 4 Site plan, plan of the 3rd ground floor, and section view of the building 


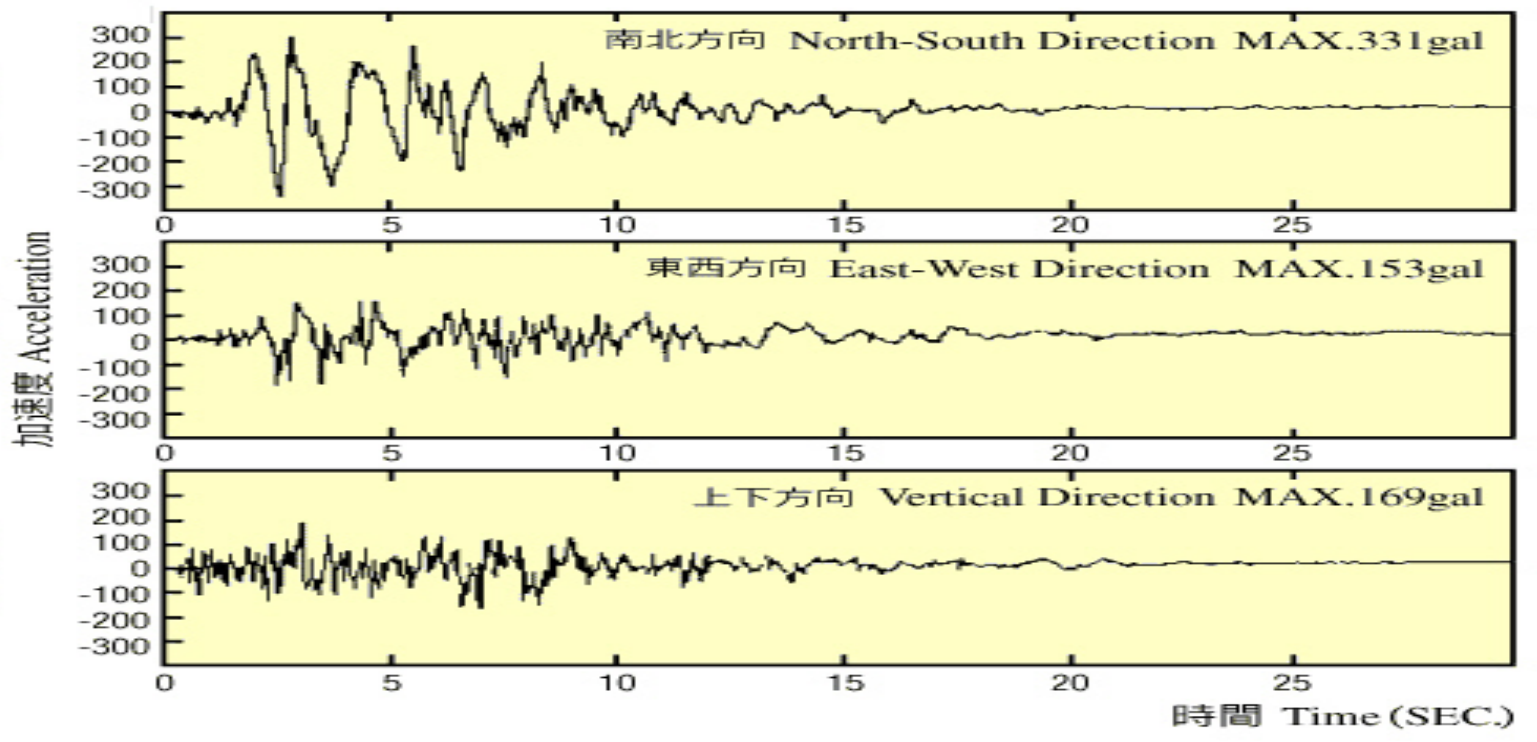

Fig. 5 Acceleration time histories of the Hyogo-ken Nanbu earthquake at the NTT Kobe Ekimae Building

\section{APPLICATION OF EARTHQUAKE DATA}

In this chapter, artificial seismic waves made from the observed data of several earthquakes are presented. These artificial seismic waves are used for seismic design and shaking table test of equipment. Fig. 6 shows acceleration response spectra with 3\% damping of the observed data on lowand middle-rise building floor since 1960 to 1984. The equipment response magnification factor against building floor, as shown in Fig. 7, is obtained by these observed data and earthquake motion including longer period waves than 1 sec like the Hyogo-ken Nanbu earthquake and response waves of high-rise and vibration controlled buildings and base isolated buildings. Fig. 8 shows the artificial seismic wave derived from the response magnification factor and random phase characteristic. The shaking table tests with artificial seismic waves have verified the seismic safety of hundreds pieces of equipment. Due to the seismic measurement, seismic tests and seismic design for equipment, facilities, and buildings, serious damages to the telecommunication system did not occur during the Hyogo-ken Nanbu earthquake.

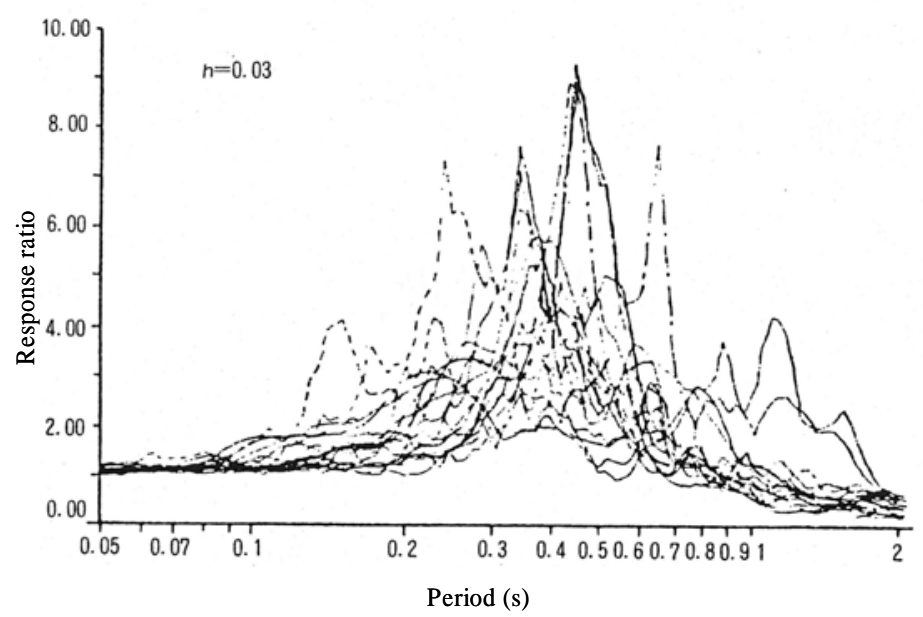

Fig. 6 Acceleration response spectra with 3\% damping of observed data on low- and middle-rise building floor 


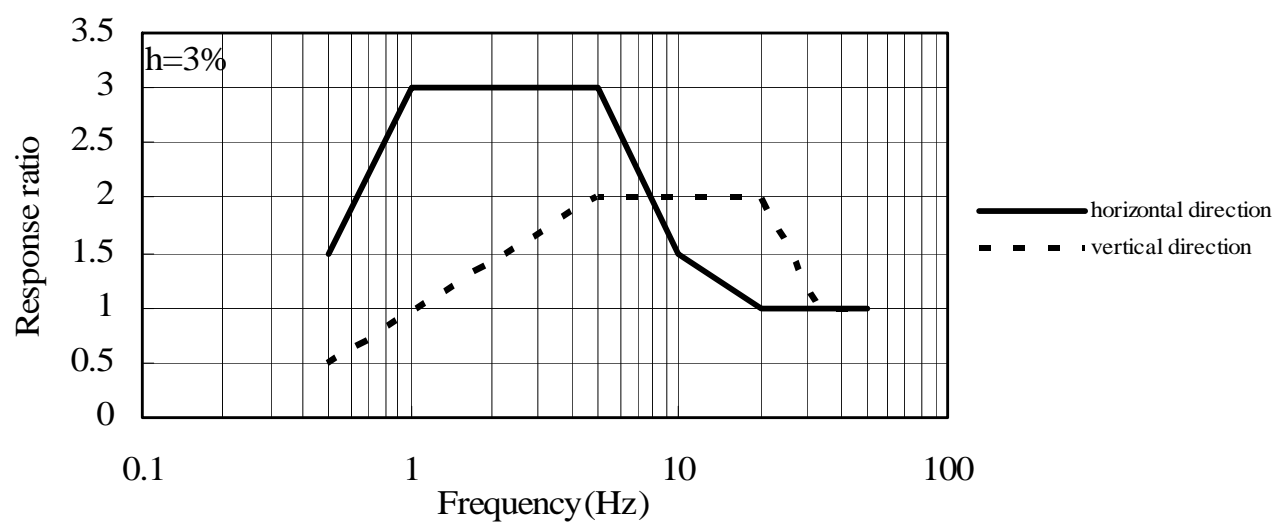

Fig. 7 Equipment response magnification factor against building floor

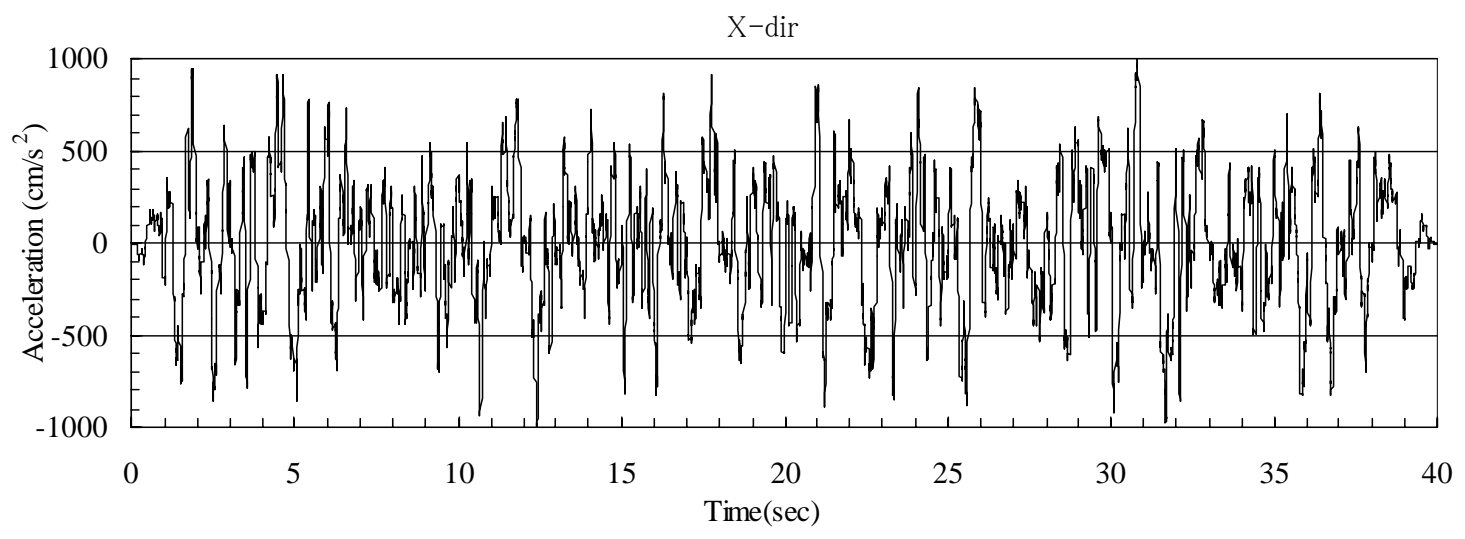

Fig. 8 Artificial seismic wave

\section{CONCLUSIONS}

NTT and NTT FACILITIES have implemented the earthquake observation systems at the 55 sites since 1960 in order to secure the reliability and safety of telecommunication. A lot of earthquake data have been obtained by these systems, and have been applied to building design and to shaking table test for equipment. Especially, the 1995 Hyogo-ken Nanbu earthquake data observed at the NTT Kobe Ekimae Building in Kobe city have widely contributed to the design of high-rise buildings and base isolated buildings.

\section{REFERENCES}

Sato, Y., Fuse, T. and Akagi, H. (1984). "Building appendage seismic design force based on observed floor." 8th World Conference on Earthquake Engineering

Inaba, T., Dohi, H., Okuta, K., Sato, T., and Akagi, H. (2000). "Nonlinear response of surface soil and NTT building due to soil-structure interaction during the 1995 Hyogo-ken Nanbu (Kobe) earthquake." Soil Dynamics and Earthquake Engineering, Vol. 20, 289-300.

(Submitted: March 19, 2004)

(Accepted: June18, 2004)

Copyright JAEE 